\title{
Predictors of mortality in patients with Alzheimer's disease living in nursing homes
}

Giovanni Gambassi, Francesco Landi, Kate L Lapane, Antonio Sgadari, Vincent Mor, Roberto Bernabei, on behalf of the SAGE Study Group

\begin{abstract}
Objectives-To identify factors associated with mortality in patients with Alzheimer's disease, and to evaluate whether these factors vary according to severity of cognitive impairment.

Methods-Data were from the SAGE database which includes information on all residents admitted between 1992 and 1995 to all Medicare/ Medicaid certified nursing homes of five US states. We conducted a longitudinal follow up study (median 23 months) on 9264 patients aged 65 years and above with a diagnosis of Alzheimer's disease. Patient data including demographic characteristics, dementia severity, comorbidity, and other clinical and treatment variables were collected with the Minimum Data Set. Information on death was derived through linkage to Medicare files. Baseline characteristics were used to predict survival in univariate and multivariate Cox proportional hazard models.
\end{abstract}

Istituto di Medicina Interna e Geriatria, Università Cattolica del Sacro Cuore, Rome, Italy G Gambassi

F Landi

A Sgadari

R Bernabei

Center for Gerontology and Health Care

Research, Brown

University,

Providence, RI, USA

G Gambassi

K L Lapane

V Mor

Department of Community Health, Brown University Medical School, Providence, RI, USA G Gambassi

K L Lapane

V Mor

Correspondence to: Dr Giovanni Gambassi, Center for Gerontology and Health Care Research, Brown University-Box G-B213, Providence, RI 02912, USA. Telephone 001 4018633211 , or 3491 ; fax 0014018633489 ; email Giovanni_Gambassi@ brown.edu

Received 1 July 1998 and in revised form

24 November 1998

Accepted 8 January 1999
Results-Overall mortality rate was $\mathbf{5 0 \%}$, with a first year rate of $25.7 \%$. Increased age (risk ratio (RR) 1.83 ; 95\% confidence interval $(95 \%$ CI) $1.65-2.03$, for patients $85+$ years), male sex (RR 1.81; 95\% CI 1.70-1.94), limitation in physical function (RR 1.45; 95\% CI 1.27-1.66), a condition of malnutrition (RR 1.31; 95\%CI 1.23-1.39), the presence of pressure ulcers (RR 1.24; 95\% CI 1.13-1.36), a diagnosis of diabetes mellitus (RR 1.32; 95\% CI 1.21-1.43), and of cardiovascular diseases (RR 1.22; 95\% CI 1.14-1.30) were independent predictors of death, regardless of the severity of baseline dementia. Sensory problems (hearing and vision) and urinary incontinence were associated with increased mortality only among patients with less severe dementia. The presence of disruptive behaviour, aphasia, and a diagnosis of Parkinson's disease were not related to survival. African-Americans and other minority groups were less likely to die relative to white people.

Conclusions-Age, sex, functional limitation, and malnutrition seem to be the strongest predictors of death for patients with Alzheimer's disease in nursing homes. Altogether, severity of dementia has no influence on survival, yet the predictive role of certain variables depends on the degree of impairment. Minority groups have a reduced risk of death relative to white people.

(F Neurol Neurosurg Psychiatry 1999;67:59-65)
Keywords: Alzheimer's disease; nursing home; mortality; minimum data set

Alzheimer's disease is the most common form of dementia, and a major healthcare problem. ${ }^{12}$ Recent evidence suggests that the prevalence of Alzheimer's disease is about 50\% in people older than 85 years. ${ }^{3}$ In the United States, it is estimated that Alzheimer's disease afflicts nearly 4 million people and is the fourth leading cause of death. ${ }^{4}$

Although estimates of the risk of death among those with Alzheimer's disease have varied greatly, most studies, both institutional ${ }^{5-7}$ and community based, ${ }^{8-14}$ have suggested that it is substantially increased relative to age and sex matched control subjects.

Several factors seem to contribute to mortality of patients with Alzheimer's disease. These include increasing age, ${ }^{78^{15-19}}$ male sex, ${ }^{7}{ }^{13} 17-20$ and functional disability. ${ }^{6} 14172122$ Some studies, but not all, have found the risk of mortality to be associated with extrapyramidal signs, ${ }^{20} 23-25$ psychiatric symptoms, ${ }^{23} 2627$ depression, ${ }^{28}$ nutritional indices, ${ }^{7} 10112930$ language loss and aphasia, ${ }^{31}{ }^{32}$ and apolipoprotein phenotype. ${ }^{33}$ The effect of severity of dementia on survival of patients with Alzheimer's disease is inconsistent; an almost equal number of studies have shown an association, ${ }^{79111314161734}$ or no relation. ${ }^{18} 19222732{ }^{35} \mathrm{Few}$ of these studies have controlled for the potential impact of comorbid conditions ${ }^{713141921}$ and the results remain inconclusive. Likewise, race was rarely considered in studies of survival of patients with Alzheimer's disease. ${ }^{8} 1736$

Thus, despite more than 100 reports describing the predictors of survival among patients with Alzheimer's disease, we remain unable to identify risk profile and to estimate reliably the length of time to death. Providing an empirically based answer would have far reaching consequences, as Alzheimer's disease has a profound effect also on the million formal and informal caregivers who assist these patients. Even more relevant would be the impact on long term care facilities where most of these patients live.

The purpose of the present study was to examine predictors of survival in a large sample of patients with Alzheimer's disease living in United States nursing homes. Specifically, we determined the role of comorbid conditions affecting these patients on survival, and evaluated whether this varies by severity of dementia. 


\section{Methods}

SAGE DATABASE

We used data from the SAGE (Systematic Assessment of Geriatric drug use via Epidemiology) database, which has been described in detail elsewhere. ${ }^{37-39}$ The SAGE is a population based, longitudinal database (1992-5) that comprises data collected with the Minimum Data Set (MDS) on residents of the nursing homes in five states (Kansas, Maine, Mississippi, New York, and South Dakota) and data on the medications used by each resident. These data have been cross linked to Medicare eligibility files to retrieve information on vital status.

The MDS is an assessment instrument that contains more than 300 items describing demographic, functional, and clinical characteristics of each resident. ${ }^{40}$ An extensive array of symptoms, syndromes, and treatments is also included, and indicators describing resident's behaviour, mood, and involvement in activities. Among others, two summary scales based on MDS items describe the level of cognitive function (cognitive performance scale $(\mathrm{CPS}))^{41}$ and residents' performance in activities of daily living (ADL scale).$^{42}$ The validity and reliability of these summary scales have been previously documented. ${ }^{43}$ The diagnoses of all comorbid conditions were coded by the staff physician or assistant physician consulting transfer documentation and medical records. The overall validity and accuracy of the diagnostic information contained in the SAGE database has been documented by reviewing Medicare's hospital discharge claims. ${ }^{39}$ Furthermore, elements of the SAGE database have been used in other epidemiological studies. ${ }^{44-46}$

STUDY POPULATION

We selected residents newly admitted to nursing homes with a diagnosis of probable Alzheimer's disease. The key criteria of the diagnostic and statistical manual of mental disorders (DSM-IV) were used for the definition of Alzheimer's disease. ${ }^{47}$ In interrater and testretest trials, diagnosis of Alzheimer's disease showed an excellent $\kappa$ coefficient $(0.81)$, and proved of research value. ${ }^{48}{ }^{49}$ Patients were at least 65 years of age at their initial MDS assessment, and we excluded patients with a history of mental retardation, mental illness or any other life long mental health disorders. This strategy yielded a sample of 9264 patients.

\section{ANALYTICAL APPROACH}

All demographic variables, measures of severity of dementia and comorbid conditions were gathered at initial MDS assessment on admission to the nursing home. Demographic variables included age, sex, race, and marital status. Measure of physical function was based on activities of daily living scores and severity of dementia was based on CPS scores. Psychological status was measured investigating whether residents showed any observable signs or indicators of delirium (less alert, changing awareness of environment, incoherent speech, lethargy, changing of cognitive ability over the course of a day). ${ }^{40}$ Residents were considered to have behaviour problems when they exhibited wandering or socially inappropriate or disruptive behaviour, or they were verbally or physically abusive. ${ }^{40}$ Comorbid conditions included cardiovascular diseases, stroke, aphasia, diabetes mellitus, malnutrition, chronic obstructive pulmonary disease, depression, Parkinson's disease, and sensory impairment affecting the ability to hear or read. Cardiovascular comorbid conditions (ischaemic heart disease, congestive heart failure, hypertension, arrhythmia) were evaluated both separately and as a combined variable. We considered body mass index, calculated using residents' body weight and height collected in the MDS, as a marker of nutritional status. This measure has shown good validity when compared with anthropometric variables. ${ }^{50}$ We also evaluated the presence of urinary incontinence, of pressure sores, and of history of falls or of use of restraints. Most variables were categorised as present or not present when examining their main effect on survival. Age was stratified in 10 year intervals, 65-74, 75-84, and 85+. ADL scores were used to group patients in three clinically meaningful strata; a score of $0-1$ was for normal functioning, a score of 2-3 identified those needing supervision, and a score of 4-5 were those who required extensive assistance in performing basic activities of living. A CPS score of 2 to 4 was considered moderate cognitive impairment, and a score of 5-6 was judged as severe impairment. These values compare with widely accepted cut offs on the mini mental state examination scale. ${ }^{43}$

We performed a survival analysis using Cox proportional hazards modelling. Time to death was calculated from the date of first MDS assessment to the date of death. Information on

Table 1 General characteristic of study population $(n=9264)$

\begin{tabular}{|c|c|}
\hline Characteristic & $\%$ \\
\hline \multicolumn{2}{|l|}{ Age (y): } \\
\hline $65-74$ & 14.4 \\
\hline $75-84$ & 48.6 \\
\hline $85+$ & 37.0 \\
\hline \multicolumn{2}{|l|}{ Sex: } \\
\hline Female & 69.2 \\
\hline \multicolumn{2}{|l|}{ Race: } \\
\hline White & 90.7 \\
\hline African-Americans & 6.5 \\
\hline Others* & 2.8 \\
\hline \multicolumn{2}{|l|}{ Marital status: } \\
\hline Married & 34.3 \\
\hline Widowed & 54.6 \\
\hline Othert & 11.0 \\
\hline \multicolumn{2}{|l|}{ Physical function (ADL score) $\ddagger$} \\
\hline Normal & 12.0 \\
\hline Need supervision & 45.1 \\
\hline Require assistance & 42.9 \\
\hline \multicolumn{2}{|l|}{ Cognitive function (CPS score) $\int$} \\
\hline Normal/minimal & 6.6 \\
\hline Moderate impairment & 58.7 \\
\hline Severe impairment & 34.7 \\
\hline \multicolumn{2}{|l|}{ Advanced directives: } \\
\hline Do not resuscitate & 40.0 \\
\hline Malnutrition $\left(\mathrm{BMI}<21 \mathrm{Kg} / \mathrm{m}^{2}\right)$ & 41.9 \\
\hline \multicolumn{2}{|l|}{ Number of diagnoses: } \\
\hline None & 11.9 \\
\hline $1-2$ & 45.3 \\
\hline $3-4$ & 30.6 \\
\hline $5+$ & 12.3 \\
\hline
\end{tabular}

^Includes Asian/Pacific islander, Hispanic, American Indian Alaska native; tincludes never married and divorced/separated; łactivities of daily living; \cognitive performance scale; $₫$ body mass index. 
Table 2 Crude and adjusted relative risks (RRs) of mortality

\begin{tabular}{|c|c|c|c|}
\hline & $\begin{array}{l}\text { Dead/alive } \\
\text { (No of patients) }\end{array}$ & $\begin{array}{l}\text { Crude model } \\
(R R(95 \% C I))\end{array}$ & $\begin{array}{l}\text { Adjusted model } \\
(R R(95 \% C I))\end{array}$ \\
\hline \multicolumn{4}{|l|}{ Age $(y)$ : } \\
\hline $65-74$ & $513 / 822$ & - & - \\
\hline $75-84$ & $2121 / 2377$ & $1.34(1.22-1.47)$ & $1.34(1.22-1.48)$ \\
\hline $85+$ & $1997 / 1434$ & $1.84(1.67-2.03)$ & $1.83(1.65-2.03)$ \\
\hline \multicolumn{4}{|c|}{$1.07(1.07=2.07)$} \\
\hline Female & $2790 / 3612$ & - & - \\
\hline Male & $1831 / 1020$ & $1.82(1.72-1.93)$ & $1.81(1.70-1.94)$ \\
\hline \multicolumn{4}{|l|}{ Race / ethnicity: } \\
\hline White & $4222 / 4031$ & - & - \\
\hline African-American & $248 / 340$ & $0.81(0.71-0.92)$ & $0.82(0.72-0.94)$ \\
\hline Other minorities & $99 / 160$ & $0.68(0.56-0.83)$ & $0.69(0.57-0.85)$ \\
\hline \multicolumn{4}{|l|}{ Marital status: } \\
\hline Widowed & $2403 / 2645$ & - & - \\
\hline Married & $1765 / 1412$ & $1.28(1.21-1.36)$ & $1.04(0.97-1.12)$ \\
\hline Other & $455 / 569$ & $0.97(0.83-1.12)$ & $0.86(0.75-0.97)$ \\
\hline \multicolumn{4}{|l|}{ Cognitive function: } \\
\hline Normal & $284 / 328$ & - & - \\
\hline Moderate impairment & $2562 / 2858$ & $1.04(0.92-1.17)$ & $1.04(0.91-1.17)$ \\
\hline Severe impairment & $1771 / 1430$ & $1.32(1.17-1.49)$ & $1.13(0.99-1.29)$ \\
\hline \multicolumn{4}{|l|}{ Behaviour problems: } \\
\hline No & $2482 / 2335$ & - & - \\
\hline Yes & $2124 / 2294$ & $0.91(0.86-0.96)$ & $0.93(0.88-1.00)$ \\
\hline \multicolumn{4}{|l|}{ Indicators of delirium: } \\
\hline No & $3606 / 3812$ & - & - \\
\hline Yes & $960 / 750$ & $1.20(1.11-1.28)$ & $1.17(1.09-1.27)$ \\
\hline \multicolumn{4}{|l|}{ Use of restraints: } \\
\hline No & $3595 / 3954$ & - & - \\
\hline Yes & $103 / 674$ & $1.39(1.29-1.49)$ & $1.03(0.95-1.11)$ \\
\hline \multicolumn{4}{|l|}{ Physical function: } \\
\hline Normal & $386 / 719$ & - & - \\
\hline Need supervision & $1943 / 2211$ & $1.56(1.40-1.74)$ & $1.25(1.11-1.41)$ \\
\hline Require assistance & $2272 / 1678$ & $2.18(1.96-2.43)$ & $1.45(1.27-1.66)$ \\
\hline \multicolumn{4}{|l|}{ Hearing problems: } \\
\hline No & $4019 / 4252$ & - & - \\
\hline Yes & $581 / 377$ & $1.44(1.32-1.58)$ & $1.10(1.00-1.21)$ \\
\hline \multicolumn{4}{|l|}{ Vision problems: } \\
\hline No & $3816 / 4099$ & - & - \\
\hline Yes & $700 / 467$ & $1.42(1.32-1.58)$ & $1.13(1.03-1.23)$ \\
\hline Urinary incontinence: & & & \\
\hline No & $1510 / 2137$ & - & - \\
\hline Yes & $3099 / 2482$ & $1.59(1.50-1.69)$ & $1.15(1.06-1.24)$ \\
\hline Pressure ulcers: & & & \\
\hline No & $4020 / 4284$ & - & - \\
\hline Yes & $606 / 345$ & $1.64(1.50-1.78)$ & $1.24(1.13-1.36)$ \\
\hline Cardiovascular disease: & & & \\
\hline No & $3056 / 3437$ & - & - \\
\hline Yes & $1575 / 1196$ & $1.36(1.28-1.44)$ & $1.22(1.14-1.30)$ \\
\hline Stroke: & & & \\
\hline No & $4140 / 4244$ & - & - \\
\hline Yes & $491 / 389$ & $1.20(1.10-1.32)$ & $1.05(0.96-1.16)$ \\
\hline Aphasia: & & & \\
\hline No & $4547 / 4583$ & - & - \\
\hline Yes & $84 / 50$ & $1.35(1.09-1.68)$ & $1.12(0.89-1.40)$ \\
\hline Parkinson's disease: & & & \\
\hline No & $4351 / 4403$ & - & - \\
\hline Yes & $280 / 230$ & $1.16(1.03-1.31)$ & $0.98(0.86-1.10)$ \\
\hline Depression: & & & \\
\hline No & $2838 / 2909$ & - & - \\
\hline Yes & $1793 / 1724$ & $1.04(0.98-1.10)$ & $1.11(1.04-1.18)$ \\
\hline COPD: & & & \\
\hline No & $4168 / 4335$ & - & - \\
\hline Yes & $463 / 298$ & $1.41(1.28-1.55)$ & $1.26(1.14-1.39)$ \\
\hline Diabetes mellitus: & & & \\
\hline No & $3962 / 4130$ & - & - \\
\hline Yes & $669 / 503$ & $1.27(1.17-1.38)$ & $1.32(1.21-1.43)$ \\
\hline Malnutrition $(\mathrm{BMI}<21)$ & & & \\
\hline No & $2420 / 2875$ & - & - \\
\hline Yes & $2126 / 1689$ & $1.35(1.27-1.43)$ & $1.31(1.23-1.39)$ \\
\hline Falls: & & & \\
\hline No & $2883 / 3067$ & - & - \\
\hline Yes & $1714 / 1537$ & $1.16(1.09-1.23)$ & $1.01(0.96-1.07)$ \\
\hline
\end{tabular}

$\mathrm{COPD}=$ chronic obstructive pulmonary disease.

date of death was derived by linking patients with the Medicare enrollment files via the health claim number present in the MDS form. We examined all events which occurred through March 1997, with a median follow up of 23 months (range 1-58). Each baseline characteristic was considered in separate proportional hazards models. Prognostic factors identified in the univariate analyses were then candidates for inclusion in the final models where we adjusted for potential confounders.
We considered confounders as any variable that altered the measure of effect of interest by more than $10 \%$. Age and sex were considered important confounders of the association between prognostic factors and survival and were always included in the adjusted models. We assessed and ruled out multicollinearity. This modelling approach was also performed stratifying patients in two groups based on CPS scores, 2 to 4 (moderate impairment), and 5-6 (severe impairment). Hazard rate ratios (RRs) and corresponding $95 \%$ confidence intervals (95\% CIs) were derived from the final models. All analyses were performed using SAS version 6.12 (Cary, NC, USA).

\section{Results}

Table 1 lists the principal baseline demographic characteristics of the sample. Patients were 82.1 (SD 6.8) years old, with over $85 \%$ aged 75 years and above. Nearly $70 \%$ of patients were women and white patients comprised the overwhelming majority $(91 \%)$ of the population. Patients had 2.5 (SD 1.8) clinical diagnoses other than Alzheimer's disease, and showed a high degree of functional impairment as indexed by the difficulty in performing activities of daily living. Forty two per cent had a BMI value $<21 \mathrm{~kg} / \mathrm{m}^{2}$. Whereas about $6 \%$ of the patients had only a minimal impairment of cognitive function, over a third $(35 \%)$ scored 5 or 6 on the CPS scale - that is, severe dementia.

During a median follow up of 23 months, 4631 patients $(50 \%)$ died; $26 \%$ dying within the first year. Table 2 presents both the crude and adjusted relative risks for each of the variables considered in this study. At univariate analysis, increased age and male sex were associated with a greater risk of mortality. Among the indices describing the overall clinical severity, limitation in physical function, presence of pressure ulcers, of urinary incontinence, use of restraints, and indicators of delirium were all associated with an increased risk. Most of the comorbid conditions considered were associated with increased mortality. These included sensory impairment (hearing and vision problems), respiratory diseases, cardiovascular diseases, aphasia, diabetes mellitus, and malnutrition.

After adjustment, age, sex, functional limitation, malnutrition, diabetes mellitus, COPD, pressure ulcers, and cardiovascular diseases remained associated with increased mortality. Minority patients were less likely to die during the follow up relative to white patients $(\mathrm{RR}=0.81$ for African-Americans and $R R=0.68$ for patients belonging to other race groups). This association persisted after adjustment for age, sex, level of impairment, and all concomitant conditions.

Table 3 shows the results of a stratified analysis to evaluate whether factors related to mortality differed by baseline cognitive impairment. Advanced age, male sex, limitation in physical functioning, malnutrition, presence of pressure ulcers, and a diagnosis of diabetes mellitus and of cardiovascular diseases were independent risk factors for mortality regard- 
Table 3 Adjusted relative risks (95\% CI), by baseline level of cognitive impairment

\begin{tabular}{|c|c|c|}
\hline & Moderate $(n=5393)$ & Severe $(n=3160)$ \\
\hline \multicolumn{3}{|l|}{ Age (y): } \\
\hline $65-74$ & - & - \\
\hline $75-84$ & $1.40(1.21-1.62)$ & $1.29(1.12-1.49)$ \\
\hline $85+$ & $1.77(1.52-2.05)$ & $1.92(1.65-2.23)$ \\
\hline \multicolumn{3}{|l|}{ Sex: } \\
\hline Female & - & - \\
\hline Male & $1.94(1.79-2.11)$ & $1.80(1.63-1.99)$ \\
\hline \multicolumn{3}{|l|}{ Race / ethnicity: } \\
\hline White & - & - \\
\hline African-American & $0.72(0.60-0.87)$ & $0.99(0.81-1.20)$ \\
\hline Other minorities & $0.69(0.52-0.92)$ & $0.64(0.47-0.87)$ \\
\hline \multicolumn{3}{|l|}{ Behaviour problems: } \\
\hline No & - & - \\
\hline Yes & $0.99(0.91-1.08)$ & $0.85(0.76-0.94)$ \\
\hline \multicolumn{3}{|l|}{ Indicators of delirium: } \\
\hline No & - & - \\
\hline Yes & $1.15(1.03-1.27)$ & $1.19(1.06-1.33)$ \\
\hline \multicolumn{3}{|l|}{ Physical function: } \\
\hline Normal & - & - \\
\hline Need supervision & $1.26(1.10-1.45)$ & $1.66(1.10-2.53)$ \\
\hline Require assistance & $1.44(1.22-1.69)$ & $1.98(1.29-3.03)$ \\
\hline \multicolumn{3}{|l|}{ Hearing problems: } \\
\hline No & - & - \\
\hline Yes & $1.12(1.00-1.27)$ & $1.06(0.94-1.26)$ \\
\hline \multicolumn{3}{|l|}{ Vision problems: } \\
\hline No & - & - \\
\hline Yes & $1.20(1.05-1.36)$ & $1.06(0.97-1.22)$ \\
\hline \multicolumn{3}{|l|}{ Urinary incontinence: } \\
\hline No & - & - \\
\hline Yes & $1.16(1.06-1.28)$ & $1.09(0.95-1.28)$ \\
\hline \multicolumn{3}{|l|}{ Pressure ulcers: } \\
\hline No & - & - \\
\hline Yes & $1.26(1.10-1.45)$ & $1.23(1.08-1.40)$ \\
\hline \multicolumn{3}{|l|}{ Cardiovascular disease: } \\
\hline No & - & - \\
\hline Yes & $1.24(1.14-1.35)$ & $1.21(1.10-1.34)$ \\
\hline \multicolumn{3}{|l|}{ Depression: } \\
\hline No & - & - \\
\hline Yes & $1.07(1.00-1.17)$ & $1.19(1.07-1.32)$ \\
\hline \multicolumn{3}{|l|}{ COPD: } \\
\hline No & - & - \\
\hline Yes & $1.28(1.13-1.45)$ & $1.18(1.00-1.42)$ \\
\hline \multicolumn{3}{|l|}{ Diabetes mellitus: } \\
\hline No & - & - \\
\hline Yes & $1.27(1.14-1.42)$ & $1.36(1.19-1.57)$ \\
\hline \multicolumn{3}{|c|}{ Malnutrition $(\mathrm{BMI}<21)$ : } \\
\hline No & - & - \\
\hline Yes & $1.33(1.22-1.44)$ & $1.30(1.17-1.43)$ \\
\hline
\end{tabular}

$\mathrm{COPD}=$ chronic obstructive pulmonary disease.

less of the severity of baseline cognitive impairment. A diagnosis of depression seemed to be a stronger predictor among patients with severe Alzheimer's disease at baseline. By contrast, sensory problems and urinary incontinence were associated with mortality if baseline cognitive impairment was only moderate. Minority groups had a consistently lower risk of mortality regardless of severity of dementia, with the exception of African-Americans with severe impairment.

The presence of any of the four behavioural problems assessed in the MDS (wandering, verbally or physically abusive, socially inappropriate) showed a trend towards inverse relation with mortality (table 2 and 3 ). When we examined specific domains separately, patients with Alzheimer's disease who showed wandering had a lower rate of mortality than those without such a behaviour problem (44\% v 53\%). By contrast, mortality rate was higher among patients exhibiting severe and aggressive behaviours (53\%).

\section{Discussion}

The present study shows that among patients with Alzheimer's disease living in long term care facilities increased mortality was related to advanced age, male sex, limitation in physical functioning, malnutrition, presence of pressure ulcers, a diagnosis of diabetes mellitus, and of cardiovascular diseases. These factors were independent predictors of mortality regardless of the severity of cognitive impairment. A diagnosis of depression seemed to be a stronger predictor among patients with severe Alzheimer's disease at baseline. Instead, sensory impairment and urinary incontinence were associated with an increased risk of mortality among patients with only moderate cognitive deficits. Minority groups, both African-Americans and other race or ethnic groups, had a lower risk of mortality, independently of severity of dementia.

In recent years, significant advances have been made in the understanding of Alzheimer's disease, yet effective treatment is not available and the progressive course of the disease cannot be reversed. Thus, considerable attention has been devoted to studies on the early mortality associated with dementia of Alzheimer type in an attempt to identify prognostic factors. Over 100 articles have described several predictors, yet studies have been incomplete and have generated inconclusive results.

We found that increased age, male sex, and white race carried an increased risk of mortality. That increased age was a prognostic factor confirms the great majority of studies published, ${ }^{16-18}$ most specifically those including very old patients such as ours, both in the community $^{19}$ but especially in nursing homes. $^{7153451}$ The notion that men with Alzheimer's disease have a substantially increased risk of mortality relative to age matched women with disease is the most consistent finding across two decades of research ${ }^{13}{ }^{17-20}$; only two studies were unable to document a sex difference. ${ }^{85}$ Yet, possible explanations for this difference remain speculative..$^{53}$ Our study is among the very few that could explore the role of different race or ethnicity. The finding of an increased risk of mortality among white people is in agreement with the paper by Chandra $e t a l^{36}$ who searched all death certificates for the years 1971 and 1973 through 1978. However, two other studies in patients with Alzheimer's disease did not find any race difference. ${ }^{817}$

Our analysis documented that physical dependency and other measures of debility (presence of pressure sores and urinary incontinence) are among the best predictors of mortality regardless of degree of cognitive impairment. We have used the activities of daily living scale and found similar results as in two previous studies ${ }^{22} 54$; yet a recent article by AgueroTorres $e t a l^{19}$ failed to confirm activities of daily living dependency as a risk factor among patients with Alzheimer's disease. None the less, the last is the only study at variance with the literature. Measures of disability that have been associated with increased mortality in other studies include the Blessed DRS, ${ }^{14} 1732$ the clinical dementia rating scale, ${ }^{28}$ decreased grip strength, ${ }^{8}$ and severe physical impairment, unstable gait, and falls. ${ }^{6}$ This supports the hypothesis that functional decline can have a 
course independent of cognitive failure, and that more general rather than specific indicators of the disease status identify high risk patients in nursing homes, ${ }^{55}$ just as in hospitals. ${ }^{56}$

We found that selected comorbid conditions (cardiovascular diseases, diabetes mellitus, and COPD) predicted higher mortality, and the association remained regardless of different levels of cognitive impairment. Composite indices of comorbidity have been inconsistently associated with mortality in demented patients. ${ }^{6} 91921$ Previous works specifically on vascular diseases found an association with hypertension, ${ }^{8}$ cardiovascular diseases, ${ }^{73} 14$ and myocardial ischaemia, ${ }^{10}$ but the findings are not universal. ${ }^{781426}$ Similarly, non-vascular comorbid conditions were associated with mortality in some studies, ${ }^{67}$ but not in others. ${ }^{91421}$ These different results may be attributable to an underrepresentation of comorbid conditions among demented patients. ${ }^{48} 57$ In agreement with the results of other authors, ${ }^{7}{ }^{14}$ sensory impairment affecting vision and hearing was associated with a slightly increased risk of mortality in our study. However, these measures are properly markers for general disability and they do not influence mortality directly.

We could not document an association between severity of dementia and mortality. Although this is an area of intense research, an equal number of studies have shown an association, ${ }^{7911} 13-1734$ or no relation, ${ }^{18} 1922273235$ with mortality of patients with Alzheimer's disease. A clear reason for such disparate findings is elusive but hypotheses have been formulated. On the one hand, the difficulty of ascertaining the age at onset of dementia may attenuate the effect of cognitive decline on survival. ${ }^{14}$ This time dependent predictability of severity of dementia would depend on a non-linear course of Alzheimer's disease. ${ }^{5758}$ Alternatively, models simultaneously adjusting for measures of disability that reflect not only functional ability but the general status of the patient might blunt the effect of severity of dementia. ${ }^{192}$ Finally, clinicopathological studies in patients with Alzheimer's disease have shown that advanced age at death is associated with somewhat less severe dementia and fewer senile plaques and neurofibrillary tangles. ${ }^{59}$ Specific areas of cognitive dysfunction, such as verbal fluency or aphasia, have been identified as predictors of mortality. ${ }^{10} 1732$ In our cohort there seemed to be a positive trend, but in agreement with other authors, ${ }^{14} 28$ aphasia was not independently associated with increased mortality. Similarly, our findings concur with recent evidence showing no, ${ }^{72023}$ or inverse ${ }^{14}$ relations between behavioural problems and mortality. The "protection" afforded by wandering is likely due to the fact that it is a marker of better physical function. ${ }^{60}$

Several indices correlated with nutritional status-anaemia, ${ }^{7}$ weight loss, ${ }^{30}$ low $\mathrm{BMI},{ }^{10} 29$ cachexia $^{11}{ }^{34}$ - have been associated with poor survival of patients with Alzheimer's disease, but the issue remains incompletely explored. ${ }^{14}$ In all models presented in our study, a condition of malnutrition was associated with increased mortality. We estimated nutritional status based exclusively on BMI calculation, which is not an accurate indicator of proteincalorie malnutrition that is expected to be the hallmark of these patients. ${ }^{61}$ None the less, MDS-based BMI measures identify patients with malnutrition. ${ }^{50}$ Malnutrition affects immune response and causes malabsorption, thus worsening nutritional status as well as reflecting the effects of the disease status. However, malnutrition is the end result of several medical and social conditions that chronically affect elderly people and it can therefore be considered a marker of frailty in demented patients. ${ }^{62}$

This study confirms some of the findings of previous studies, but it is at variance with others. A possible explanation for these differences may be due to the study setting. Indeed studies of patients admitted to long term care institutions may result in selective identification of those patients more severely affected by the disease. Another source of variation is the difference in the criteria used to diagnose Alzheimer's disease.$^{63}$ In the present study, the diagnosis was confirmed on review of hospital discharge record documentation and was likely consistent with the criteria for the clinical diagnosis of probable Alzheimer's disease developed by the NINCDS-ADRDA working group. In a nursing home study similar to ours, a panel of experts reviewing clinically relevant information confirmed in nearly $80 \%$ of cases the diagnosis made by lay evaluators. ${ }^{64}$ In our study the diagnosis was made clinically and we lack any pathological data. However, severe fallacies have been reported in the pathological confirmation of the diagnosis of Alzheimer's disease. ${ }^{656}$ Finally, criteria used to screen dementia severity, performance in physical function, and the definition of factors tested as predictors have also varied widely in previous studies.

Some limitations of the present study should be considered. Although patients were drawn from a broad geographic area in the United States and had standardised and validated assessment, they are not necessarily representative of all patients affected by Alzheimer's disease. However, with respect to the generalisability of our results, or lack thereof, van DjiK et $a l$ found very similar findings among 606 demented patients admitted to a Dutch nursing home facility. Moreover, our focus has been on prevalent and not on incident cases of Alzheimer's disease. As the use of prevalent cases tends to exclude those with rapidly progressive disease and short survival, we cannot exclude that selective survival explains all or part of the results found. However, it is likely that this results in an underestimation of the effect of the disease on mortality. The analytical strategy adopted is not devoid of potential pitfalls. Although we studied predictors using a longitudinal approach, information was gathered at initial MDS assessment, impeding the examination of time dependent predictors. False associations between mortality and baseline variables could have occurred by chance owing to the analysis of several variables. For 
this reason we included only a subset of variables selected a priori from a larger set of MDS data. We based the selection on the findings of previous studies, and on the likelihood that a variable might affect survival. Furthermore, future studies would have to investigate whether and how the effect of medical factors on mortality varies according to sociodemographic variables. Despite a large cohort of patients, we may have had insufficient power to detect a true difference with some variables that were uncommon in this population (aphasia). Finally, as we assessed whether predictors differed by cognitive impairment without a formal test for interaction, independence cannot be ascertained conclusively.

In conclusion, this study expands our knowledge of the prognostic determinants in patients living in nursing homes and provides useful information about the clinical course of Alzheimer's disease. Although there are many risk factors for mortality in this elderly population, the factors with the strongest association with mortality seem to be those with the greatest potential for modification. For caregivers, these results suggest that efforts should be made to minimise these factors. A "high-tech" intervention would hardly ever be justifiable; likewise a "nihilistic" approach is not appropriate.$^{67}$ Intervention aimed at improving physical conditioning, optimising function in activities of daily living, considering malnutrition, and preventing pressure sores should be considered as they may considerably improve the quality of life of demented patients. Further studies will also have to clarify discordant results about the impact of some of these intervention programmes on functional wellbeing and survival. ${ }^{68-70}$

The Systematic Assessment of Geriatric drug use via Epidemiology (SAGE) Study Group is composed by the following: steering committee: R Bernabei, C Gatsonis, L Lipsitz, V Mor; codirection: G Gambassi, K Lapane; members: D Forman, D Gifford, F Landi, A Sgadari; data management: J Hiris, C Grostrup-Jensen, S Gonzales; biostatistics: C Gatsonis, J Hogan, O Intrator; participants: K Berg, L Culpepper, A Hume, P Larratt, J Murphy, K Steel.

1 National Institute on Aging. Progress on Alzheimer's disease, 1996. Washington, DC: National Institute on Aging, National Institutes of Health, US Department of Health and Human Services:1996. (NIH publication 96-4137.)

2 Morrison-Bogorad M, Phelps C, Buckholtz N. Alzheimer disease research comes of age. The pace accelerated. ҰAMA 1997;277:837-40.

3 Small GW, Rabins PV, Barry PP, et al. Diagnosis and treatment of Alzheimer disease and related disorders. $7 A M A$ 1997;278:1363-71.

4 Cullum CM, Rosenberg RN. Memory loss: when is it Alzheimer disease? FAMA 1998;279:1689-90.

5 Barclay LL, Zemcov A, Blass JP, et al. Survival in Alzheimer's disease and vascular dementias. Neurology Alzheimer's disea

6 Martin DC, Miller JK, Kapoor W, et al. A controlled study of survival with dementia. Arch Neurol 1987;44:1122-6.

7 VanDijk PT, van de Sande HJ, Dippel DW, et al. The nature of excess mortality in nursing home patients with dementia. F Gerontol 1992;47:M28-34.

8 Hier DB, Warachg JD, Gorelick PB, et al. Predictors of survival in clinically diagnosed Alzheimer's disease and multiinfarct dementia. Arch Neurol 1989;46:1213-6.

9 Walsh JS, Welch HG, Larson EB. Survival of outpatients with Alzheimer-type dementia. Ann Intern Med 1990;113 429-34.

10 Nielsen H, Lolk A, Pedersen I, et al. The accuracy of early diagnosis and predictors of death in Alzheimer's disease and vascular dementia: a follow-up study. Acta Psychiatr Scand 1991;84:277-82.

11 Evans DA, Smith LA, Scherr PA, et al. Risk of death from Alzheimer's disease in a community population of older persons. Am $\mathcal{F}$ Epidemiol 1991;134:403-12.
12 Katzman R, Hill LR, Yu ESH, et al. The malignancy of dementia: predictors of mortality in clinically diagnosed dementia in a population survey of Shanghai, China. Arch Neurol 1994;51:1220-5.

13 Jagger CJ, Clarke M, Stone A. Predictors of survival with Alzheimer's disease: a community-based study. Psychol Med 1995;25:171-7.

14 Bowen JD, Malter AD, Sheppard L, et al. Predictors of mortality in patients diagnosed with probable Alzheimer's disease. Neurology 1996;47:433-9.

15 Volicer BJ, Hurley H, Fabiszewski KJ, et al. Predicting short-term survival for patients with advanced Alzheimer's disease. F Am Geriatr Soc 1993;41:535-40.

16 Stern Y, Tang M-X, Denaro J, et al. Increased risk of mortality in Alzheimer's disease patients with more advanced educational and occupational attainment. Ann Neurol 1995;37:590-5.

17 Heyman A, Peterson B, Fillenbaum G, et al. The consortium to establish a registry for Alzheimer's disease (CERAD) Part XIV: demographic and clinical predictors (CERAD) Part XIV: demographic and clinical predictors
of survival in patients with Alzheimer's disease. Neurology of survival in patient

18 Reisberg B, Ferris SH, Franssen EH, et al. Mortality and temporal course of probable Alzheimer's disease: a 5-year prospective study. Int Psychogeriatr 1996;8:291-311.

19 Aguero-Torres H, Fratiglioni L, Guo Z, et al. Prognostic factors in very old demented adults: a seven-year follow-up from a population-based survey on Stockholm. F Am Geriatr Soc 1998;46:444-52.

20 Stern Y, Tang M-X, Albert MS, et al. Predicting time to nursing home care and death in individuals with Alzheimer disease. FAMA 1997;277:806-12.

21 Bianchetti A, Scuratti A, Zanetti O, et al. Predictors of mortality and institutionalization in Alzheimer disease patients 1 year after discharge from an Alzheimer dementia unit. Dementia 1995;6:108-12.

22 Hebert M, Parlato V, Lese GB, et al. Survival in institutionalized patients: influence of dementia and loss of functional alized patients: influence of dementia and
capacities. Arch Neurol 1995;52:469-76.

23 Stern Y, Albert M, Brand J, et al. Utility of extrapiramidal signs and psychosis as predictors of cognitive decline and functional decline, nursing home admission, and death in Alzheimer's disease: prospective analyses from the predictors study. Neurology 1994;44:2300-7.

24 Van DijK PTM, Dippel DWJ, van der Meulen JP, Habbema JDF. Comorbidity and its effect on mortality in nursing home patients with dementia. $\mathcal{F}$ Nerv Ment Dis 1996;184: $180-7$.

25 Bennett DA, Beckett LA, Wilson RS, et al. Parkinsonian signs and mortality from Alzheimer's disease. Lancet 1998; 351:1631.

26 Barclay LL, Zemcov A, Blass JP, et al. Factors associated with duration of survival in Alzheimer's disease. Biol Psychiatry 1985;20:86-93.

27 Moritz DJ, Fox PJ, Luscombe FA, et al. Neurological and psychiatric predictors of mortality in patients with Alzheimer's disease in California. Arch Neurol 1997;54: 878-85

28 Burns A, Lewis G, Jacoby R, et al. Factors affecting survival in Alzheimer's disease. Psychol Med 1991;21:363-70.

29 Chandra V, Bharucha NE, Schoenberg BS. Conditions associated with Alzheimer's disease at death: case-control study. Neurology 1986;36:209-11.

30 Wang SY, Fukagawa N, Hossain M, et al. Longitudinal weight changes, length of survival, and energy requirements of long term care residents with dementia. $\mathcal{f} \mathrm{Am}$ Geriatr Soc 1997;45:1189-95.

31 Huff FJ, Belle SH, Shim YK, et al. Prevalence and prognostic value of neurologic abnormalities in Alzheimer's disease. Dementia 1990;1:32-40.

32 Bracco L, Gallato R, Grigoletto F, et al. Factors affecting course and survival in Alzheimer's disease. A 9-year longitudinal study. Arch Neurol 1994;51:1213-9.

33 Tilvis RS, Strandberg TE, Juva K. Apolipoprotein E phenotypes, dementia and mortality in a prospective population sample. F Am Geriatr Soc 1998;46:861-8

34 Brodaty H, McGilchrist C, Harris L, et al. Time until institutionalization and death in patients with dementia. Role of caregiver training and risk factors. Arch Neurol 1993;50: 643-50.

35 Becker JT, Boller F, Lopez OL, et al. The natural history of Alzheimer's disease. Description of study cohort and accuracy of diagnosis. Arch Neurol 1994;51:585-94.

36 Chandra V, Bharucha NE, Schoenberg BS. Patterns of mortality from types of dementia in the United States, 1971 tality from types of dementia in the Unt
and 1973-8. Neurology 1986;36:204-8.

37 Bernabei R, Gambassi G, Mor V. The SAGE database: introducing functional outcomes in geriatric pharmacoepidemiology. $₹ \mathrm{Am}$ Geriatr Soc 1997;45:250-2.

38 Bernabei R, Gambassi G, Lapane K, et al. Characteristics of the SAGE database: a new resource for research on outcomes in long-term care. F Gerontol Med Sci 1999;54A: M25-M33.

39 Gambassi G, Landi F, Peng L, et al. Validity of diagnostic and drug data in standardized nursing home resident assessments: potential for geriatric pharmacoepidemiology. Med Care 1998;36:167-79.

40 Minimum data set plus training manual. Natick, MA, USA: Eliot Press, 1991.

41 Morris JN, Fries BE, Meher DR, et al. MDS cognitive performance scale. F Gerontol 1994;49:M174-82.

42 Mor V, Branco K, Fleishman J, et al. The structure of social engagement among nursing home residents. F Gerontol 1995;50:P1-8. 
43 Hartmaier SL, Sloane PD, Guess HA, et al. Validation of the minimum data set cognitive performance scale: agreement with the mini-mental state examination. $f$ Gerontol 1995;50:M128-33.

44 Gambassi G, Lapane K, Sgadari A, et al. Prevalence, clinical correlates, and treatment of hypertension in elderly nursing home residents. Arch Intern Med 1998;158:2377-85.

45 Bernabei R, Gambassi G, Lapane K, et al. Management of pain in elderly patients with cancer. FAMA 1998;279: 1877-82.

46 Gambassi G, Sgadari A, Lapane K, et al. Measuring health outcomes for older people using the SAGE database. Can $\mathcal{F}$ Aging 1999 (in press)

47 American Psychiatric Association. Diagnostic and statistical manual of mental disorders, revised 3rd ed. Washington, DC: APA, 1987

48 Landi F, Gambassi G, Lapane KL, et al. Comorbidity and drug use in cognitively impaired elderly living in long-term care. Dement Geriatr Cogn Disord 1998;9:347-56.

49 Landi F, Gambassi G, Lapane K, et al. Impact of type and severity of dementia on hospitalization and survival of eldseverity of dementia on hospitalization and survival of eld-

50 Blaum CS, O'Neill E, Clements KR, et al. Validity of the minimum data set for assessing nutritional status in nursing minimum data set for assessing nutritional status in

51 Heeren TJ, van Hemert AM, Rooymans HGM. A community-based study of survival in dementia. Acta Psychiatr Scand 1992;85:415-8.

52 Morrison JH, Hof P. Life and death of neurons in the aging brain. Science 1997;278:412-9.

53 Gambassi G, Lapane K, Landi F, et al. Gender differences in the relation between comorbidity and mortality of Alzheimer's disease patients. Neurology (in press).

54 Knopman DS, Kitto J, Deinard S, et al. Longitudinal study of death and institutionalization in patients with primary degenerative dementia. 7 Am Geriatr Soc 1988;36:108-12.

55 Flacker JM, Kiely DK. A practical approach to identifying mortality-related factors in established long-term care resimortality-related factors in established lo

56 Inouye SK, Peduzzi PN, Robison JT, et al. Importance of functional measures in predicting mortality among older

57 Guccione AA, Felson DT, Anderson JJ, et al. The effects of special medical conditions on the functional limitations of elders in the Framingham study. Am 7 Public Health 1994;84:351-8.

58 Brooks JO, Kraemer HCH, Tanke ED, et al. The methodology of studying decline in Alzheimer's disease. $\mathcal{F}$ 3;41:623-8

59 Berg L, McKeel DW, Miller P, et al. Clinicopathologic studies in cognitively healthy aging and Alzheimer disease. Arch Neurol 1998;55:326-35.

60 Kiely DK, Morris JN. Resident characteristics associated with wandering behavior in nursing home. $7 \mathrm{Am}$ Geriatr Soc (in press).

61 Wolf-Klein GP, Silverstone FA, Lansey SC, et al. Energy requirements in Alzheimer's disease patients. Nutrition 1995;11:264-8.

62 Antonelli Incalzi R, Landi F, Bruno E et al. Nutritional assessment: a primary component of multidimensional (1) Soc 1996;44:166-74.

63 Erkinjuntti T, Ostbye T, Steenhuis R, et al. The effect of different diagnostic criteria on the prevalence of dementia. $N$ Engl f Med 1997;337:1667-74.

64 Magaziner J, Zimmerman SI, German P, et al. Ascertaining dementia by expert panel in epidemiologic studies of nursing home residents. Ann Epidemiol 1996;6:431-7.

65 Nolan KA, Lino MM, Seligmann AW, et al. Absence of vascular dementia in an autopsy series from a dementia clinic. f Am Geriatr Soc 1998;46:597-604

66 Bowler JV, Munoz DG, Merskey H, et al. Fallacies in the pathological confirmation of the diagnosis of Alzheimer's disease. F Neurol Neurosurg Psychiatry 1998;64:18-24.

67 Teno JM, Landrum K, Lynn J. Defining and measuring outcomes in end-stage dementia. Alzheimer Dis Assoc Disord 1997;11(suppl 6):25-9.

68 Sano M, Ernesto C, Thomas RG, et al. A controlled trial of selegiline, $\alpha$-tocoferol, or both as treatment for Alzheimer's disease. N Engl f Med 1997;336:1216-22.

69 Franzoni S, Frisoni GB, Boffelli S, et al. Good nutritional oral intake is associated with equal survival in demented oral intake is associated with equal survival in demented 1996;44:1366-70.

70 Mitchell SL, Kiely DK, Lipsitz LA. The risk factors and impact on survival of feeding tube placement in nursing home residents with severe cognitive impairment. Arch Intern Med 1997;157:327-32 